\title{
A Static Analysis-Based Prediction Method of the Maximum Out-of-Plane Inelastic Seismic Response for Steel Arch Bridges
}

\author{
Osman Tunc CETINKAYA*, Shozo NAKAMURA**, Kazuo TAKAHASHI***
}

\begin{abstract}
This paper presents a method to estimate the maximum inelastic out-of-plane seismic response of upper-deck steel arch bridges. The method employs equal energy assumption to predict the maximum response without the need of dynamic response analysis. Firstly, applicability of equal energy assumption to upper-deck steel arch bridges is examined numerically by performing free vibration analysis, pushover analysis, and elastic and inelastic dynamic response analyses. The models with different arch-rise to span ratio and arch rib spacing are generated and the influence of these parameters on the applicability of the assumption is studied. Although the assumption resulted in conservative side estimation, in many cases the results were too conservative to be practical for the design practice. On the other hand, some tendencies that make it possible to develop some correction functions to improve the estimation accuracy of equal energy assumption were found regardless any parameters. Finally, by using the proposed correction functions and the response spectra a method that doesn't require dynamic response analysis for the estimation of maximum inelastic seismic demand is developed and its validity is evidenced by numerical analyses.
\end{abstract}

Keywords: Seismic Design, Equal Energy Assumption, Steel Arch Bridges, Pushover Analysis, Dynamic Response Analysis.

\section{Introduction}

The Hyogo-ken Nanbu earthquake of 17 January 1995, which was more severe earthquake than that

\footnotetext{
*Graduate Student, Nagasaki University Graduate School of Science and Technology (1-14, Bunkyo-machi, Nagasaki 852-8521)

**Corresponding Author. Associate Professor, Nagasaki University, Department of Civil Engineering (1-14, Bunkyo-machi, Nagasaki 852-8521) E-mail: snakamura@civil.nagasaki-u.ac.jp Tel. \& Fax: $+81-95-819-2613$

***Professor, Nagasaki University, Department of Civil Engineering (1-14, Bunkyo-machi, Nagasaki $852-8521)$
} 
considered in the design code for structures, caused destructive damage to many structures [1]. Steel bridges were no exception. The range of damage included the collapse of steel bridge piers, as well as local buckling of stiffened box and pipe sections. Since this devastating earthquake, many efforts to improve the seismic performance of steel structures have been made in Japan. These efforts began with the simplest and most common structures such as cantilevered steel piers and portal frame piers. The strength and ductility of these structures under cyclic loading has been examined experimentally or numerically [2-5]. By the time the trend has shifted to clarify the inelastic seismic behavior of more rare but complex structures, such as steel truss [6], arch [7-14] and elevated bridges [15,16]. Recently, also, more interest is being given in the development and application of vibration control devices to structures [17]. Some findings have been introduced into the revised version of the Japanese seismic design code for highway bridges (JRA code) [18, 19]. The design ground motion was also revised and a two-level seismic design method is now specified for, respectively, moderate (called Level-I) and extreme (called Level-II) ground motions [18, 19].

Steel arch bridges were conventionally treated as structures for which earthquake loading is not predominant, as they are normally built in mountainous areas with little chance of major earthquakes, since ocean-type earthquakes are common in Japan. Moreover, even if experienced, earthquake excitation was not thought to be crucial, because arches are structures of relatively long natural period and are generally built on rock foundations. For this reason, conventional design took into consideration only moderate earthquakes, during which the structure should remain in the elastic range. However, the new provision for design based on Level-II ground motions for all bridges in Japan has made it necessary also to understand the inelastic behavior of steel arch bridges, since severe earthquake loading could put them in a critical situation. There are some earlier papers on the seismic response of steel arch bridges [7-14]. Usami et al. [12] investigated the inelastic seismic performance of a typical upper-deck steel arch bridge subjected to major earthquakes. They found that seismic responses are small under longitudinal ground motion input but severe plasticization and performance deficiencies are observed under transverse excitation. This study proves that Level-II ground motion can be critical for upper-deck steel arch bridges.

Meanwhile, the compulsory evaluation of inelastic behavior greatly complicates the design process compared to conventional practice. The powerful method of non-linear dynamic response (time-history) analysis is the most rigorous way to carry out seismic response estimation. However, implementation is 
time consuming, which hampers its wide application to everyday design. There is a desire for a method of seismic design that does not rely on dynamic response analysis. The JRA code specifies a simplified method called the Ductility Design Method, which is based on static analysis. This is a force-based design procedure utilizing elastic analysis in which a force reduction factor is adopted to account for inelastic behavior. The force reduction factor is calculated using the equal energy assumption [20], which assumes the elastic energy stored in the elastic and inelastic systems is identical. However the application of this method is limited only to simple structures, because the applicability of the equal energy assumption is not clear in the case of structures with complex dynamic response characteristics. In the JRA code, simple dynamic behavior implies that the structure is a system with a predominant first vibration mode and the possible location of the primary plastic hinge can be easily foreseen. This confines use of the method to reinforced concrete piers and steel piers in-filled with concrete. For other structures, referred to as 'complicated structures' by the JRA code (including steel arch bridges), dynamic response analysis should be conducted for seismic performance verification. Lu et al. $[\mathbf{1 3}, \mathbf{1 4}]$ proposed a simplified seismic design verification procedure based on pushover analysis and dynamic response analysis of an equivalent single-degree-of-freedom system for upper-deck steel arch bridges. Although the method is very reliable, it is still necessary to carry out dynamic response analysis.

A displacement-based inelastic seismic response prediction procedure for upper-deck steel arch bridges that requires no dynamic response analysis is proposed in this paper. The equal energy assumption is adopted for the maximum response estimation. The applicability of the equal energy assumption is investigated as a first step toward prediction of maximum inelastic out-of-plane response. The examination is conducted numerically on six upper-deck steel arch bridge models by comparing estimation results with the results of dynamic response analysis.

There have been some previous reports on the applicability of the equal energy assumption to steel bridges. Usami et al. [21] examined the applicability of both equal-energy and equal-displacement assumptions through pseudo-dynamic tests of cantilevered columns in steel bridge piers. They found that a fairly good estimation of nonlinear response was achieved by using the equal energy assumption, while the response predicted by the equal-displacement assumption was much smaller than in the actual tests.

Nakajima et al. [22] investigated the applicability of the equal energy assumption to the seismic design of 
steel portal frames. The paper concludes that it gives a safe-side estimation of the maximum nonlinear response, but the estimated maximum displacement can be much larger than that given by elasto-plastic dynamic response analysis. Nakamura et al. [23] also investigated the applicability of the equal energy assumption to steel portal frames. Their study showed that the equal energy assumption results in a conservative prediction of maximum response, with the results being too conservative in many cases. They also suggested some correction functions that improve estimation accuracy.

The upper-deck steel arch bridges studied in this paper also yield conservative estimates when the equal energy assumption is applied, as explained in the text that follows. In fact, estimated response is much larger than the actual response in many cases, making the accuracy of the assumption quite low. However some solid tendencies regarding estimation accuracy are found, and this makes it possible to develop certain correction functions that improve the accuracy. Having improved the estimates obtained with the equal energy assumption, the correction functions are combined with the elastic response spectrum to predict the maximum inelastic seismic response without the need of dynamic response analysis.

\section{Applicability of Equal Energy Assumption}

\subsection{Analyzed models}

The applicability of the equal energy assumption is examined numerically by studying six upper-deck steel arch bridge models. The models differ in their arch-rise to span ratio and arch rib spacing, as shown in

Table 1. These two structural parameters are given variations over a wide coherent range in order to obtain a pattern representing the behavior of general upper-deck steel arch bridges and also to examine their influence on the applicability of the equal energy assumption.

Model 1 shown in Figure 1 is used as the template from which the other five parametric models are generated. This bridge was adopted by the JSSC committee as a representative model for investigations of nonlinear behavior during major earthquakes [24]. The parametric models are generated by using the JSP-15 W preliminary design software for steel arch bridges [25]. Models 2-4 are generated from Model 1 by changing only the arch rise. Models 5 and 6 are generated from Model 1 by changing only the spacing between the two arch ribs. The generation process is carried out carefully, in order to ensure that the newly generated models remain within realistic limits. The selected arch-rise to span ratios can be found in 
existing steel arch bridges. The template Model 1 and newly generated Models 2-4 carry two-lane traffic. The distance between the arch ribs is widened in order to carry a three-lane deck in Model 5, and a four-lane deck in Model 6. In this way, realistic steel arch bridge models are generated for numerical analysis. Models 1, 2, 3 and 4 constitute a pattern demonstrating the effect of arch-rise to span ratio, whereas Models 1, 5 and 6 are a series demonstrating the effect of arch rib spacing on the applicability of the equal energy assumption.

Figure 1 also gives the cross sections of the main structural elements of the template model. A box-type section is used for the arch rib and side column, whereas an I-section is adopted for the stiffening girder. The figure shows the cross section of the arch rib near the support and that of the stiffening girder in the span center. The side columns have a uniform box section. The other five generated models have cross sections of the same shape based on dimensions given by the preliminary design software.

The bridges are modeled and analyzed using the general purpose MARC nonlinear finite element (FE) analysis software [26]. Three-dimensional beam elements of type 14 and 79, as provided in the MARC element library, are employed to model the structural members. Element 14 is adopted for the box sections. This is a closed-section straight-beam element with no warping of the section but including twist based on Euler-Bernoulli beam theory. There are two nodes per element. The degrees of freedom associated with each node are three global displacements and three global rotations. Element 79 is used for the I-shaped sections. It is an open-section straight-beam element that includes warping and twisting of the section. It is composed of two nodes with seven associated degrees of freedom, three for global displacements, three for global rotations and one for warping of the section.

Material nonlinearity is taken into account by 3D fiber modeling. For the box sections of the arch ribs, 26 integration points are specified. There are 24 integration points for the side columns and 25 for the I-shaped sections. Geometrical nonlinearity is also taken into account in the FE analysis. The updated Lagrangian Formulation is employed to consider the large displacement effect.

The boundary conditions and connection types of the bridge models are shown in Figure 2. Typical boundary conditions are used for all of the models. As for the abutments, roller bearings are assumed in the longitudinal direction. The side pier ends consist of pivot-type bearings and the arch rib ends are pinned bearings. All connections between the members are rigid. 
A lumped mass approach is used to model the mass of the bridges. The masses of the stiffening girder, arch ribs and piers are lumped at their nodal points. Further, the masses of the transverse and diagonal members are also considered; these are lumped on the nodal points of the corresponding stiffening girder, arch rib or vertical member. No rotational inertia is associated with the nodal points.

The reinforced concrete bridge deck is not modeled, but its mass is considered and lumped at the nodal points of the stiffening girder. Simpler models in which the deck is not modeled can be used in studying the applicability of the equal energy assumption because the individual effect of the reinforced concrete deck to the estimation accuracy is thought to be negligible; since the same no-deck model is used for both the estimation procedure and the time history analysis. As will be explained later in section 2.2, the accuracy of this assumption is assessed by comparing the estimated inelastic response using the equal energy assumption with the calculated response obtained from inelastic dynamic response analysis.

A single type of steel, JIS-SMA490, is adopted for all of the bridge models (yield stress $\sigma_{y}=355 \mathrm{MPa}$; Young's modulus, $E=206 \mathrm{GPa}$; Poisson's ratio, $v=0.3$ ). A bilinear stress-strain relation with a strain hardening slope $E^{\prime}=E / 100$ and a kinematic hardening rule is assumed, as seen in Figure 3 .

The natural frequencies, modal participations and mode definitions of the first 10 modes of all the analyzed models are listed in Table 2 . Since dynamic response in the out-of plane direction is the concern of this study, only the eigenmodes of the transverse direction are evaluated. The first and third out-of-plane modes make the greatest contribution as they have the largest effective mass ratios. These are selected as the predominant modes and their shapes are illustrated in Figure 4. This shows that they are symmetric out-of-plane modes and they exhibit similar shapes for the different models, despite differences in arch rise and deck width. Of these two modes, the contribution of the first one is much greater. When the effective mass ratios of this mode for Models 1, 2, 3 and 4 (which differ only in arch rise) are compared, it can be seen that the contribution increases as the arch-rise to span ratio increases. The ratio is about $60 \%$ for Model 1, increasing to about $72 \%$ for Model 4 . This suggests that a bridge will have a greater tendency to vibrate mainly in the first out-of-plane mode as the arch-rise to span ratio increases. It can also be seen, by comparing the effective mass ratios of Model 1,5 and 6, that the arch rib spacing does not significantly affect the modal contribution of the predominant modes. 


\subsection{Examination procedure}

The accuracy of estimations made by the equal energy assumption is assessed by comparing the estimated inelastic maximum response with the value obtained using nonlinear dynamic response analysis. The examination procedure is described below.

1) Free vibration analysis is carried out to obtain the principle natural frequencies and mode shapes.

2) Elasto-plastic finite displacement pushover analysis is performed in order to obtain the curve for the relationship between total out-of-plane base shear force and displacement for each model.

3) The maximum elastic response displacement is obtained by performing elastic dynamic response analysis. The corresponding total base shear force, which is the total out-of-plane reaction force summed over all supports at the maximum response displacement, is also calculated. Using these two values, the maximum strain energy stored in the structure is computed.

4) The maximum inelastic response displacement $\delta_{S P}$ is estimated by applying the equal energy assumption to the curve of total out-of-plane base shear force versus displacement, as obtained in 2) above, and the maximum strain energy, obtained in 3) (See Figure 5).

5) Inelastic finite displacement dynamic response analysis is used to obtain the maximum inelastic response displacement $\delta_{D P}$.

6) The estimated maximum response displacement $\left(\delta_{S P}\right)$ and the calculated value $\left(\delta_{D P}\right)$ are compared in order to evaluate the accuracy of the assumption.

For the pushover analysis, the modal force distribution from the single dominant mode in the transverse direction (the first symmetric out-of-plane mode) is adopted as the lateral load distribution pattern, expressed as:

$$
\left\{H_{i}\right\}=\left\{m_{i} \phi_{i}\right\}
$$

in which $m_{i}$ is concentrated mass and $\phi_{i}$ is the transverse component of the eigenvector $\{\phi\}$ at node $i$.

The modal force distribution is used here as it serves as a sufficiently accurate pattern in pushover analysis to approximate the inertia force distribution during earthquake excitations as shown by Lu et. al. $[13,14]$. In these references, the inertia force distribution, which is the lateral inertia force distribution at 
the moment of maximum displacement demand in an elastic Level-II dynamic response analysis, is evaluated as an alternative lateral load distribution pattern, expressed as:

$$
\left\{H_{i}\right\}=\left\{-m_{i} a_{i}\right\}
$$

in which $H_{i}, m_{i}$ and $a_{i}$ are the lateral force, concentrated mass and lateral acceleration at node $i$, respectively. Although it is believed that this load distribution pattern represents the actual inertia force distribution under earthquake excitations well, the dynamic response analysis requirement that the acceleration at each node be obtained makes this option unsuitable in this study, remembering that the main goal is to eliminate dynamic response analysis from seismic design.

The mid point of the stiffening girder is adopted as the reference point for pushover analysis since the maximum transverse displacements for all models are observed at this point. Through the pushover analysis, the displacement of this reference point is plotted against total base shear force in the out-of-plane direction for all supports to obtain the inelastic behavior of the structure.

Six Level-II, Type-II ground motions are used for the dynamic response analysis: three for ground condition I (stiff ground) and three for ground condition II (moderate ground). Their titles and maximum accelerations are summarized in Table 3. These ground motions are the standard ground motions specified in the JRA code $[18,19]$ for use in the seismic design of highway bridges in Japan. They were generated by modifying the near-fault strong ground motions recorded at various locations during the Hyogo-ken Nanbu earthquake to fit the specified response spectrum for Level-II ground motions illustrated in Figure 6. The response spectrum specified for the damping ratio $\xi=0.05$ can be modified for other damping ratios by multiplying the original spectrum by modification factor for damping constant $c_{D}$, which is given by the code as:

$$
c_{D}=\frac{1.5}{40 \xi+1}+0.5
$$

where $\xi$ is the assumed modal damping ratio of the structure.

The above-mentioned input ground motions are applied to the structure in the out-of-plane direction. Additionally, they are amplified by the coefficients shown in Table 3 to obtain sufficiently inelastic response. By this method, a pattern reflecting the effects of increasing ground motion intensity can be studied, for the evaluation of the applicability of the equal energy assumption. These ground motions are 
applied to the supports of the structure uniformly in the same phase, although there are some studies pointing out that out-of-phase ground motion inputs may influence the response of arch bridges [27, 28]. The JRA code does not require consideration of the influence of out-of-phase ground excitations in the seismic design of bridges shorter than $200 \mathrm{~m}$ in span.

Newmark's $\beta$ method [29] is employed to solve the equation of motion for both elastic and inelastic dynamic response analyses. The $\beta$ value is taken as $1 / 4$. Rayleigh damping [29] is assumed for all of the models by considering only the predominant eigenmodes and assuming modal damping ratios of 0.03 .

The whole examination procedure is carried out for the reference point mentioned before. The equilibrium energy equation is drawn for this point on the curve of total out-of-plane base shear force versus displacement obtained in the pushover analysis in order to estimate the maximum inelastic response. The reference point is simply used to obtain a control value of displacement, from which the deformed shape of the whole structure can be predicted. The total absorbed energy of the structure is already taken into account by employing a modal force distribution pattern as a substitute for the total dynamic response.

\subsection{Validity of using pushover analysis to represent dynamic behavior}

It is necessary to verify that dynamic behavior is sufficiently well represented by pushover analysis in which a modal force distribution is used as a lateral loading pattern. For this purpose, the displacement distribution obtained by pushover analysis is compared with that obtained from the nonlinear dynamic response. This comparison is carried out for each model using the most severe dynamic excitation. The displacement distribution obtained in the dynamic response analysis at the time increment representing the maximum response at the reference point is compared with the distribution given by pushover analysis at the static force increment corresponding to the same reference point displacement. The comparisons are given in Figure 7 for the stiffening girder and the arch rib of each model, respectively. These comparisons demonstrate that the displacement distributions match each other quite closely (although there are some differences in the case of Model 3). It can be concluded that pushover analysis carried out using a modal force distribution based on the first out-of-plane vibration mode with an effective mass ratio of more than 60\% suitably accounts for dynamic behavior, matching the findings of Lu et al. [14]. 


\subsection{Accuracy of estimation and influencing parameters}

The ratio of estimated maximum inelastic response $\left(\delta_{S P}\right)$ to the actual dynamic response calculated by inelastic dynamic response analysis $\left(\delta_{D P}\right)$ is used as an index of estimation accuracy. The applicability of the equal energy assumption is studied by evaluating the relationship between this estimation accuracy index $\left(\delta_{S P} / \delta_{D P}\right)$ and estimated ductility factor $\left(\mu_{E}\right)$. The estimated ductility factor is expressed as

$$
\mu_{E}=\delta_{S P} / \delta_{y}
$$

in which $\delta_{S P}$ is the estimated maximum nonlinear response and $\delta_{y}$ is the yield displacement obtained by pushover analysis. The ductility ratio $\mu\left(\mu=\delta_{D P} / \delta_{y}\right)$ can be used instead of $\mu_{E}$ to evaluate applicability once inelastic dynamic response analysis has been carried out. However, such an approach would not appropriate for this study, whose objective is to find an alternative to dynamic response analysis for the prediction of inelastic maximum response.

The $\delta_{S P} / \delta_{D P}-\mu_{E}$ relationships for the different models are illustrated together for various input ground motions in Figure 8. The results on the right represent estimation accuracy for more ground motions with greater magnification. It can be seen that the $\delta_{S P} / \delta_{D P}$ ratio is greater that 1.0 in all cases. This means that the equal energy assumption offers a safe-side estimation. However, in many cases, the estimated results are much larger than the responses calculated by inelastic dynamic response analysis; that is, the accuracy of the estimation is quite low. In these cases, the ductility factors may appear larger than is practical for any actual design procedure. But it should be noted that $\mu_{E}$ is not the same as the ductility ratio, $\mu$, obtained through dynamic response analysis. The estimated ductility factor $\mu_{E}$ includes estimation errors that may be more than $300 \%$ in some cases. In the case of Models 5 and 6 , however, the ductility ratios are also too large for the ground condition I motions amplified by a factor of 5, especially with the Le2.t211 excitation. The values of ductility ratio, $\mu$, range from 5 to 6 , which are impractical for the design procedure. These values can simply be excluded from consideration.

Observation of the $\delta_{S P} / \delta_{D P}-\mu_{E}$ relationships shown in Figure 8 clearly shows that, for all input ground motions, they exhibit a similar tendency to reduced estimation accuracy as the estimated ductility factor $\mu_{E}$ increases. The trend is almost the same for all models, despite their different structural parameters. This 
suggests that the structural parameters considered in this study, which are the ratio of arch rise to span and the arch rib spacing, have no significant influence on the applicability of the assumption.

The JRA code recommends using at least three ground motions per dynamic analysis, taking an average of them to evaluate response for seismic design. This means it is necessary to calculate the average of the estimated responses for three ground motions for each ground condition, respectively. This also gives a better understanding of the influence of the structural parameters considered in this research. In Figure 9 the relationship between $\delta_{S P} / \delta_{D P}$ and $\mu_{E}$ for the average estimated response displacements is shown for both ground conditions. It is clear that there is no significant difference in estimation accuracy among the different models and that the relationship can be roughly represented by a linear function. Further, the overall tendency is similar for both ground conditions, suggesting that estimation accuracy is not significantly influenced by the structural parameters and input ground conditions.

\subsection{Approximation of relationship between $\delta_{S P} / \delta_{D P}$ and $\mu_{E}$}

Having shown that estimation accuracy does not depend on the model or the type of ground condition, it is possible to approximate the relationship between $\delta_{S P} / \delta_{D P}$ and $\mu_{E}$ using a single function that represents the overall trend for different ground motions and structural parameters. This approximation is achieved by taking into account only the average response displacement results, as recommended in the JRA code. The average and lower bound values of $\delta_{S P} / \delta_{D P}$ are marked in Figure 10 by lines. The average approximation is the optimum line through the $\delta_{S P} / \delta_{D P}$ values as calculated by the least squares method. On the other hand, the lower bound approximation is the bottom boundary line of the $\delta_{S P} / \delta_{D P}-\mu_{E}$ relationship. By the help of these lines it is possible to predict the estimation accuracy for any given $\mu_{E}$ value.

\subsection{Correction functions for equal energy assumption}

Estimation accuracy can be improved by modifying the approximations in the relationship between $\delta_{S P} / \delta_{D P}$ and $\mu_{E}$. By this method, a correction function $f\left(\mu_{E}\right)$ is proposed for both the average estimation and the lower bound estimation. The average estimation correction function (5), which is obtained by modifying the average approximation, is proposed to give the optimum estimation results, whereas the lower bound estimation correction function (6) is obtained from the lower bound approximation and guarantees that the estimated maximum inelastic response is always equal to or greater than the actual inelastic response $\left(\delta_{D P}\right)$. 
Estimation results are corrected by simply multiplying the estimated maximum inelastic response by the correction function of the desired type, as shown in equation (7).

\section{$\underline{\text { Average Estimation }}$}

$$
f\left(\mu_{E}\right)=1 /\left(0.1843 \mu_{E}+0.8159\right), \quad\left(0<f\left(\mu_{E}\right) \leq 1\right)
$$

\section{Lower Bound Estimation}

$$
\begin{aligned}
& f\left(\mu_{E}\right)=1 /\left(0.1700 \mu_{E}+0.7050\right), \quad\left(0<f\left(\mu_{E}\right) \leq 1\right) \\
& \delta_{S P}^{\prime}=f\left(\mu_{E}\right) \times \delta_{S P}
\end{aligned}
$$

Where, $f\left(\mu_{E}\right)$ : correction function; $\mu_{E}$ : estimated ductility factor; $\delta_{S P}^{\prime}$ : corrected value of estimated maximum response.

A correction function should be used if its calculated value for a given $\mu_{E}$ is less than or equal to 1 . Otherwise no correction is needed and the estimated value can be used as it is. This is generally encountered in the very small values of $\mu_{E}$ or when the response is completely elastic.

Corrected values of the estimated ductility factor, as calculated from the average response displacements for both ground conditions, are plotted in Figure 11 against the ductility ratio $(\mu)$, together with the values without correction. It can be seen that estimation accuracy is significantly improved as the corrected ductility factor becomes closer to the actual ductility ratio. The established correction functions are also applied to the results for individual ground motions, as shown in Figure 12. Although the correction functions are generated only by considering the average response displacements, it can be seen that estimation accuracy is also improved for the individual input ground motions. The lower bound estimation is not plotted since it is meaningful only for design procedure in which the average of three ground motion response displacements should be taken.

\section{Proposed Prediction Method}

\subsection{Prediction procedure}

In the preceding chapter, the applicability of the equal energy assumption when used with the proposed correction functions is verified for the estimated maximum response. During the application procedure, the maximum elastic response, which is necessary for prediction of the maximum nonlinear response, is obtained by performing linear dynamic response analysis in order to achieve the most accurate 
estimate possible on the basis of the assumption. However, it is desirable to carry out seismic design without dynamic response analysis for reasons of calculation time and cost. This is possible if the elastic response is estimated from the response spectrum.

The basic steps in the proposed method for predicting the maximum inelastic response are given in Figure 13 and explained below.

Step 1.Establish a FE model for the upper-deck steel arch bridge under investigation.

Step 2. Perform eigenvalue analysis to acquire the predominant free vibration mode. Based on this, calculate the force distribution to be used as the lateral force pattern in pushover analysis.

Step 3. Obtain the relationship between total out-of-plane base shear force and displacement as well as the yield displacement $\delta_{y}$ by performing pushover analysis using the modal force distribution obtained in Step 2.

Step 4. Obtain the maximum response from the response spectrum specified in the JRA code for Level-II ground motion depending on the corresponding ground condition and modal damping ratio. Calculate the corresponding elastic strain energy.

Step 5. Estimate the maximum inelastic response displacement $\delta_{S P}$ by applying the equal energy assumption and calculate the estimated ductility factor $\mu_{E}$.

Step 6. Calculate the value of correction function $f\left(\mu_{E}\right)$ either for the average estimation or the lower bound estimation. If $f\left(\mu_{E}\right)$ is less than 1 , multiply $\delta_{S P}$ by $f\left(\mu_{E}\right)$ to get the final value of maximum inelastic response. If $f\left(\mu_{E}\right)$ is greater than 1 , no correction is necessary and $\delta_{S P}$ can be used directly.

\subsection{Validity of the method}

In order to illustrate the accuracy of the proposed method, the estimated maximum nonlinear response $\delta_{S P}^{\prime}$ it yields is compared with the actual maximum dynamic response $\delta_{D P}$ calculated directly by nonlinear dynamic response analysis. This comparison is shown for the average estimation in Figure $\mathbf{1 4}$ for ground conditions I and II, respectively. The estimation error range is around $\pm 20 \%$ for the individual ground motions and $\pm 15 \%$ for the average response displacements. The lower bound estimation is studied only for average response displacements, as indicated before, and the error in this case is found to be less than $20 \%$ as shown in Figure 15. Judging from these figures, it is considered that the proposed method is applicable 
to the preliminary design of upper-deck steel arch bridges as a simple way of predicting their maximum response.

For further confirmation of its validity, the proposed method is applied to the same models using a different set of ground motions. These are ground motions not considered during the development of the correction functions. Type I ground motions for ground conditions I and II, amplified by factors of 1.5, 2 and 5, are employed as the input ground motions in this examination. The estimation obtained, $\delta_{S P}$, are compared with the actual dynamic response, $\delta_{D P}$, in Figure 16. The results for average response displacements are within the error range of $\pm 20 \%$. It can be also seen that fairly good estimation results are obtained for individual ground motions. These findings verify the proposed method for type I ground motions in addition to type II. However, it should be noted that the lower bound estimation results, which are supposed to fall on the safe side, are given as less than the actual response in a few cases.

\section{Concluding Remarks}

Static pushover analysis, linear and nonlinear dynamic response analysis of six upper-deck steel arch bridges were carried out. On the basis of the results, the applicability of the equal energy assumption for out-of-plane response of the structures was examined, and correction functions were developed to improve the estimation accuracy of the maximum response displacement. Based on these correction functions and the response spectrum, a prediction method for maximum inelastic out-of-plane seismic response of upper-deck steel arch bridges was proposed that does not rely on dynamic response analysis. The validity of the proposed method was evaluated through numerical examples. The main findings of this research are summarized below:

1) The predicted maximum inelastic response displacement based on the equal energy assumption is conservative for upper-deck steel arch bridges. In many cases, though, the results may be too conservative.

2) The ground condition type and the structural parameters considered in this investigation (ratio of arch rise to span and arch rib spacing) have no significant influence on the applicability of the equal energy assumption.

3) The prediction accuracy of the equal energy assumption can be improved by using the proposed correction functions. 
4) The proposed method of predicting maximum inelastic out-of-plane seismic response displacement can be successfully applied to upper-deck steel arch bridges as shown in the numerical examples. It is considered that this method will be useful as a simplified prediction method of maximum inelastic response for the preliminary seismic design of upper-deck steel arch bridges.

This investigation is based on numerical studies of six representative bridges covering the realistic range of applicability of upper-deck steel arch bridges. The authors believe that the method will give satisfactory results if the dynamic characteristics of the bridge being designed are similar to the ones studied here. That is, if the natural frequency is within the studied range and the modal composition is similar in that it has one dominant out-of-plane vibration mode. Although natural frequency may be considered an index of general structural stiffness, differences in the stiffness configuration of local members as well as different boundary conditions may result in different plasticization behavior of the structure, causing the accuracy of the proposed method to be reduced. However, even though extra work is necessary to elucidate the specific limits of applicable range, it is considered that the proposed method may prove useful as a preliminary design method for a certain range of upper-deck steel arch bridges.

In future work, a complete simplified design method based on a displacement demand and capacity comparison will be developed by combining this seismic demand estimation method with a suitable capacity prediction tool. The scope of the investigation will also be broadened to include the in-plane response of the structure.

\section{References}

[1] Kawashima K, Unjoh S. The damage of highway bridges in the 1995 Hyogo-ken nanbu earthquake and its impact on Japanese seismic design. Journal of Earthquake Engineering 1997; 1(3):505-541.

[2] Gao S, Usami T, Ge H B. Ductility of steel short cylinders in compression and bending. Journal of Engineering Mechanics (ASCE) 1998; 124(2):176-183.

[3] Liu Q, Kasai A, Usami T. Two hysteretic models for thin walled pipe-section steel bridge piers. Engineering Structures 2001; 23(2):186-197.

[4] Usami T, Gao S, Ge H. Elastoplastic analysis of steel members and frames subjected to cyclic loading. Engineering Structures 2000; 22(2):135-145. 
[5] Li X S, Goto Y. A three dimensional nonlinear seismic analysis of frames considering panel zone deformation. Journal of Structural Mechanics and Earthquake Engineering (JSCE) 1998; 605(I-45):1-13.

[6] Nonaka T, Usami T, Sakamoto Y, Iwamura M. Inelastic seismic behavior of upper-deck steel truss bridges under major earthquakes and a proposal for its seismic upgrading. Journal of Structural Engineering (JSCE) 2003; 49A:531-542 [in Japanese].

[7] Nonaka T, Usami T, Yoshino H, Sakamoto Y, Torigoe T. Elasto-plastic behavior and improvement of seismic performance for upper-upper-deck steel arch bridge models. Journal of Structural Mechanics and Earthquake Engineering (JSCE) 2003; 731(I-63): 31-49.

[8] Nonaka T, Ali A. Dynamic response of half-through steel arch bridge using fiber model. Journal of Bridge Engineering (ASCE) 2001; 6(6):482-488.

[9] Yanagi T, Nakajima A, Saiki I. Two-dimensional elasto-plastic behavior of upper-deck steel arch bridge and its modeling. Journal of Structural Engineering (JSCE) 2003; 49A: 543-552. [in Japanese]

[10] Okumura T, Goto Y, Ozawa K. Ultimate in-plane behavior of upper-upper-deck steel arch bridges under seismic loads. Journal of Structural Engineering (JSCE) 2000; 46A:1333-1342. [in Japanese]

[11] Sakakibara Y, Kawashima K, Shoji G. Analytical evaluation of an upper-upper-deck two-hinge steel arch bridge. Journal of Structural Engineering (JSCE) 2000; 46A: 1333-1342. [in Japanese]

[12] Usami T, Lu Z, Ge H, Kono T. Steel performance evaluation of steel arch bridges against major earthquakes. Part 1: Dynamic analysis approach. Earthquake Engineering and Structural Dynamics 2004; 33: 1337-1354.

[13] Lu Z, Usami T, Ge H. Seismic performance evaluation of steel arch bridges against major earthquakes. Part 2: simplified verification procedure. Earthquake Engineering and Structural Dynamics 2004; 33: $1355-1372$.

[14] Lu Z., Ge H., Usami T. Applicability of pushover analysis-based seismic performance evaluation procedure for steel arch bridges. Engineering Structures 2004; 26: 1957-1977.

[15] Kudo T, Saiki I, Nakajima A. Elasto-plastic behavior of viaduct system under bi-directional earthquake motions. Proceedings of the third international workshop performance-based seismic design and retrofit of transportation facilities, Tokyo, Japan; 2002; 89-99 
[16] Zhu P, Abe M, Fujino Y. Modelling three-dimensional non-linear seismic performance of elevated bridges with emphasis on pounding of girders. Earthquake Engineering and Structural Dynamics 2002; 31(11):1891-1913

[17] Chaudhary M T A, Abe M, Fujino Y. Investigation of a typical seismic response of a base-isolated bridge. Engineering Structures 2002; 24(7):945-953

[18] Japan Road Association (JRA). Specifications for highway bridges, Part V. Seismic design, Tokyo, Japan; 1996.

[19] Japan Road Association (JRA): Specifications for highway bridges, Part V. Seismic design, Tokyo, Japan; 2002.

[20] Veletsos, A S, Newmark, N M: Effect of inelastic behavior on the response of simple systems to earthquake motions, Proceedings of the Second World Conference on Earthquake Engineering, Tokyo $1960 ; 895-912$.

[21] Usami T, Saizuka K, Kiso E. and Ito Y. Pseudo-dynamic tests of steel bridge pier models under severe earthquake, Journal of Structural Mechanics and Earthquake Engineering 1995; 519/I-32: 101-113 [In Japanese].

[22] Nakajima A, Onodera O. A study on elasto-plastic behavior of steel portal frames under severe earthquake and applicability of equal energy assumption to its seismic design. Proceedings of the Second Symposium on Nonlinear Numerical Analysis and its Application to Seismic Design of Steel Structures 1998; 135-142 [In Japanese].

[23] Nakamura S, Ida Y, Takahashi, K. A prediction method of maximum inelastic seismic response for steel portal frame bridge piers. Proceedings of the First International Conference on Steel \& Composite Structures 2001; 2: 1047-1054.

[24] Usami T, editor. Seismic performance evaluation procedures and upgrading measures for steel bridges, Task Committee of Performance-Based Seismic Design Methods for Steel Bridges. Tokyo (Japan): Japan Society of Steel Construction (JSSC); 2003 [in Japanese].

[25] Input Manual for JSP-15W version 2.04. JIP Techno Science Corporation; 2003 [in Japanese].

[26] MARC User Manual Volume A- Volume E, version K7. MARC Analysis Research Corporation; 1997. 
[27] Hao H. Arch Responses to Correlated Multiple Excitations. Earthquake Engineering and Structural Dynamics 1993; 22: 389-404.

[28] Zanardo G, Pellegrino C, Bobisut C, Modena C. Performance Evaluation of Short Span Reinforced Concrete Arch Bridges. Journal of Bridge Engineering (ASCE) 2004; 9(5):424-434.

[29] Chopra A K. Dynamics of structures, 2nd ed. Prentice Hall; 2001. 


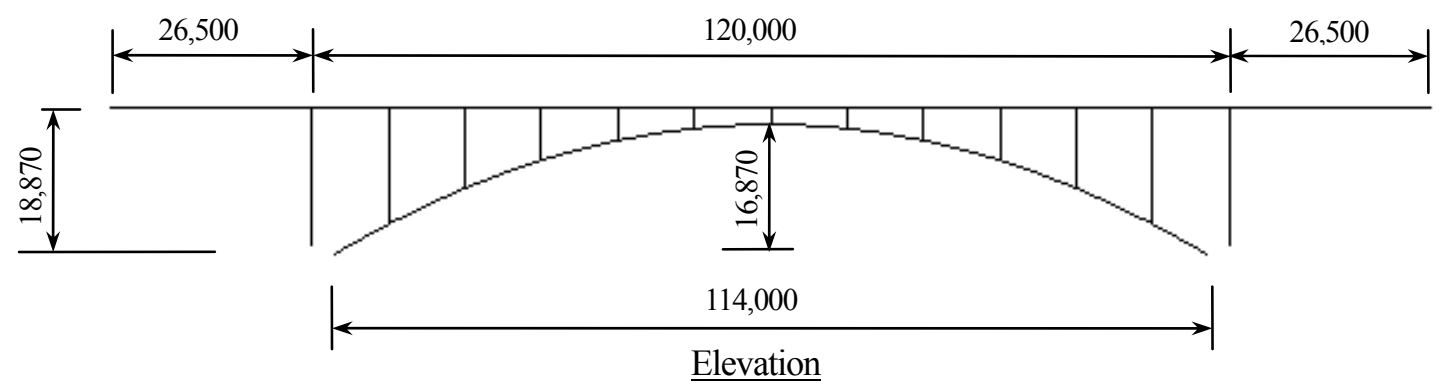

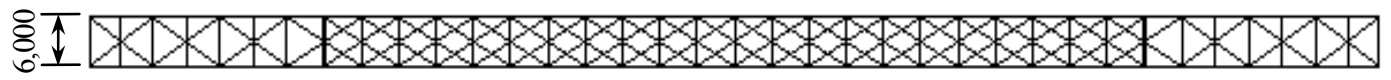

$\underline{\text { Plan }}$

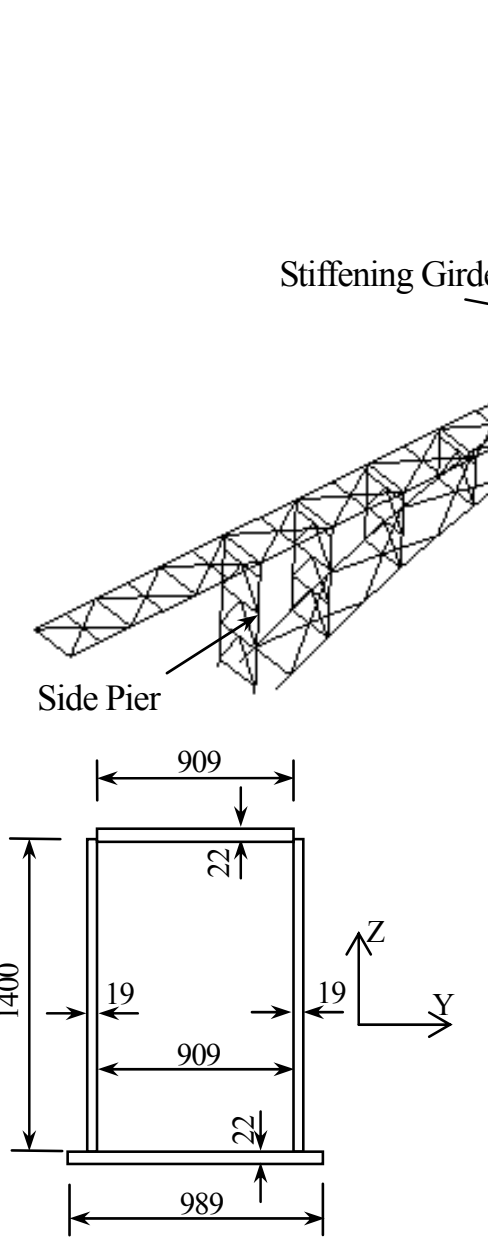

Box Section for Arch

$\underline{\text { Ribs }}$
Three dimensional view

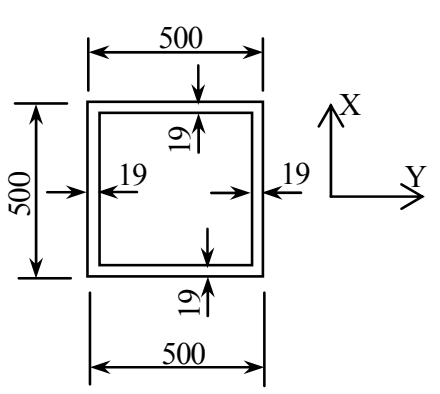

Box-Section for Side

$\underline{\text { Piers }}$

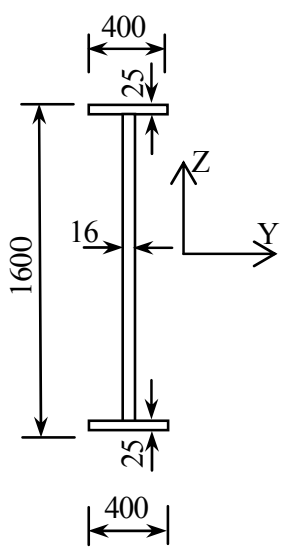

$\underline{\text { I-Section for Stiffening }}$ Girders

Figure 1: Model 1 


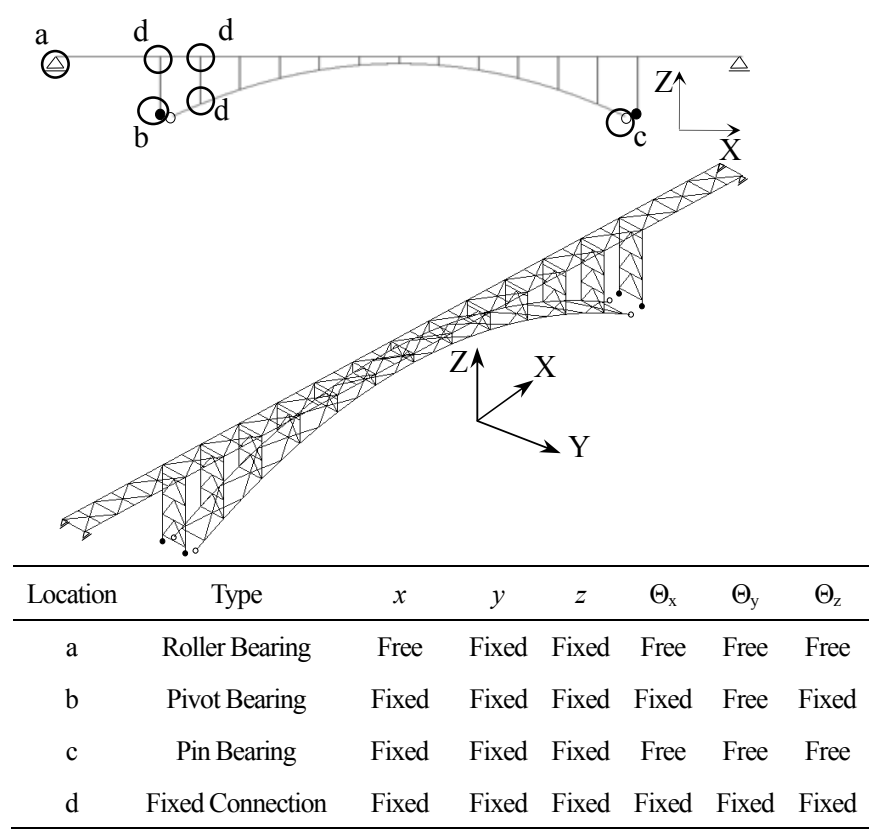

Figure 2: Boundary and connection conditions

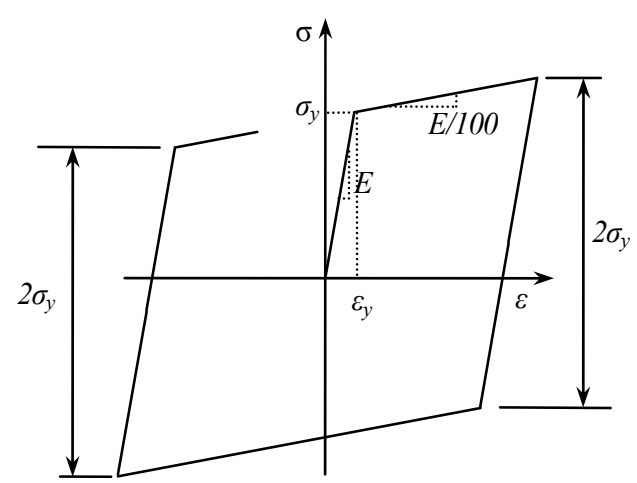

Figure 3: Material model for steel 


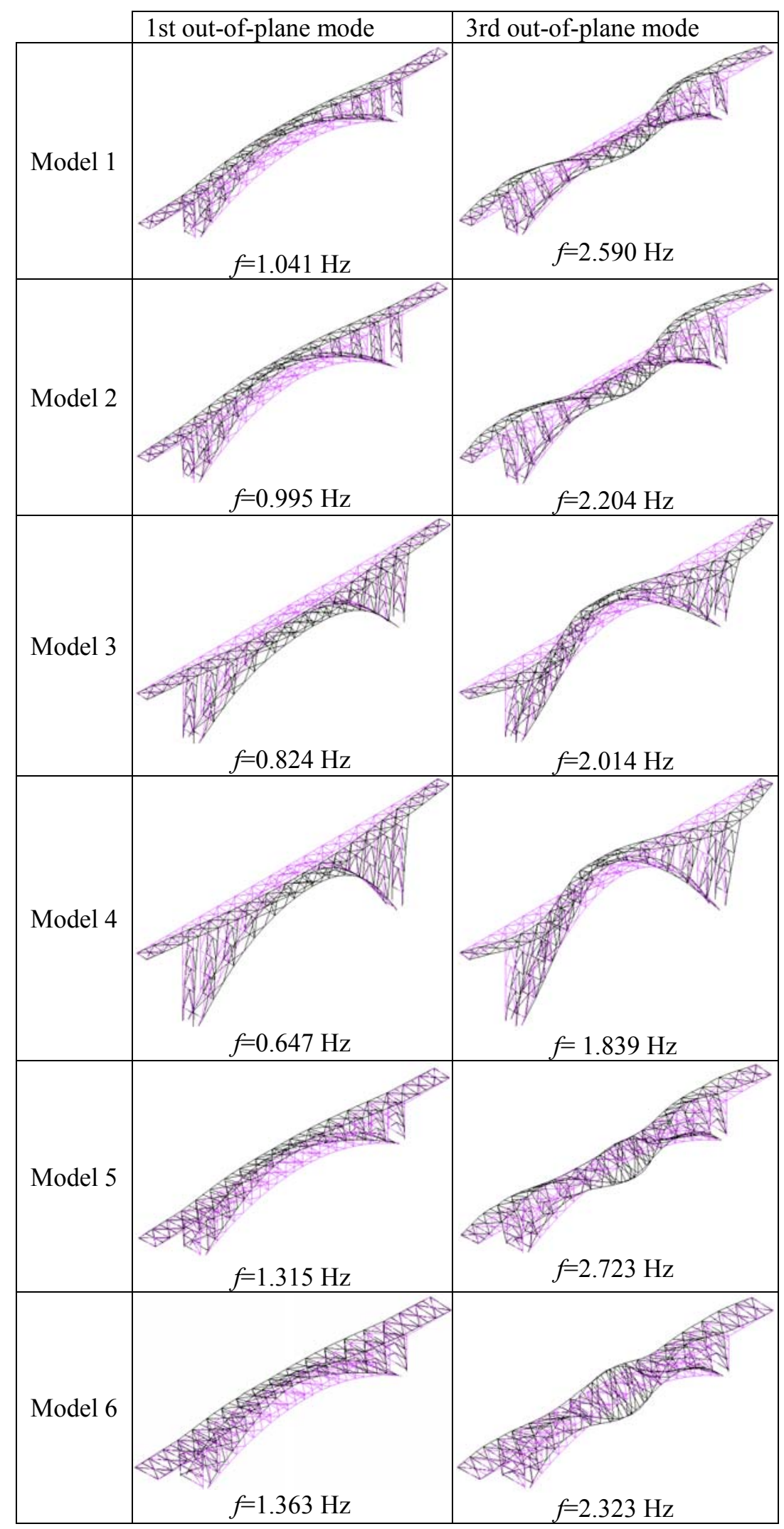

Figure 4: Predominant eigenmodes 


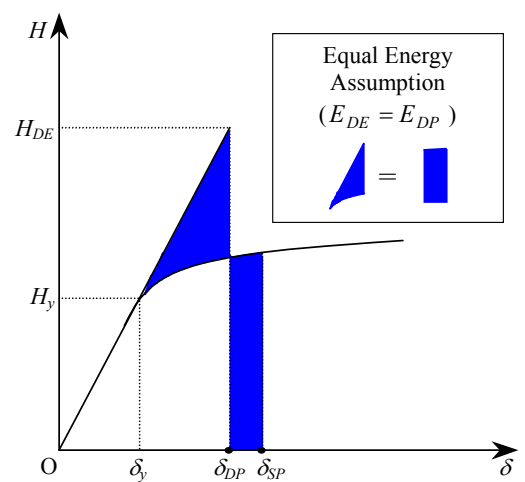

Figure 5: Equal energy assumption

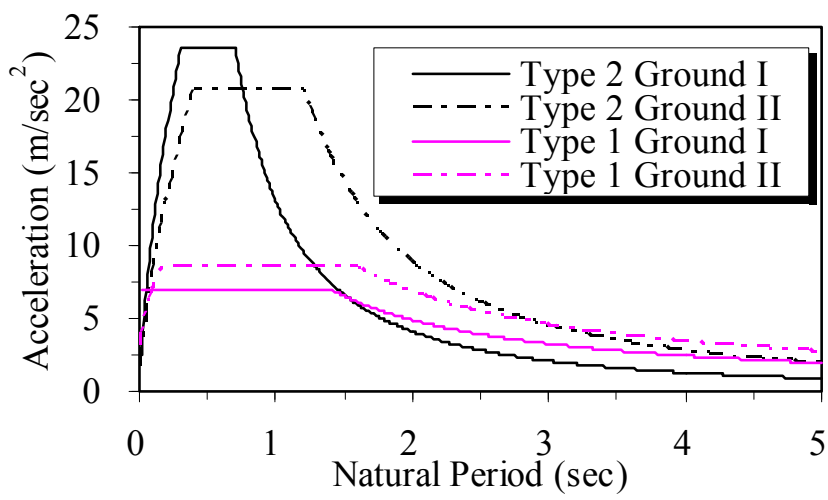

Figure 6: Standard acceleration response spectra for $\xi=0.05$ 


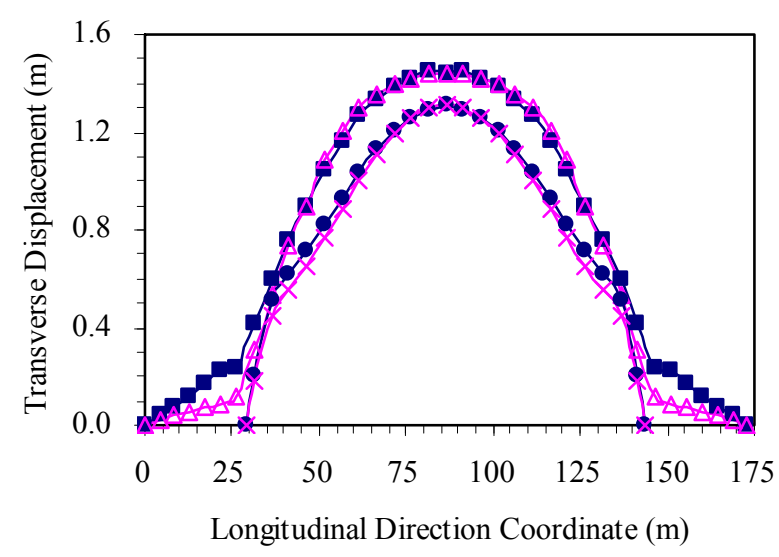

(a) Model 1

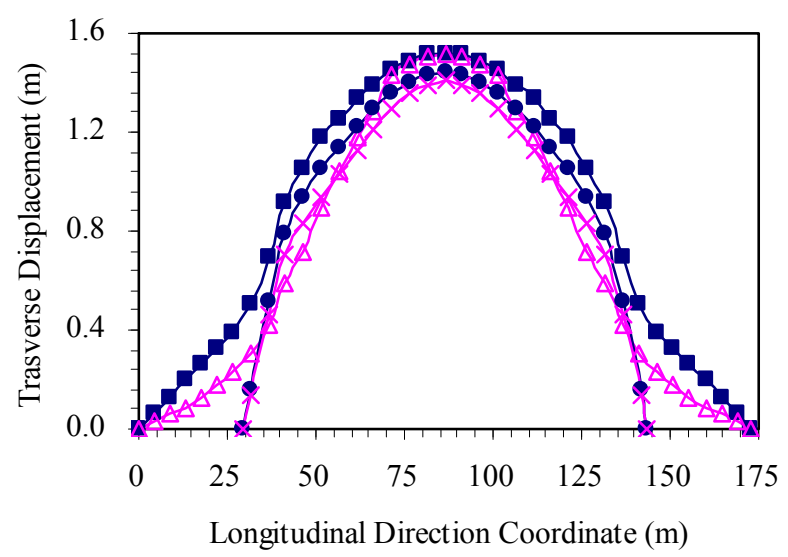

(c) Model 3

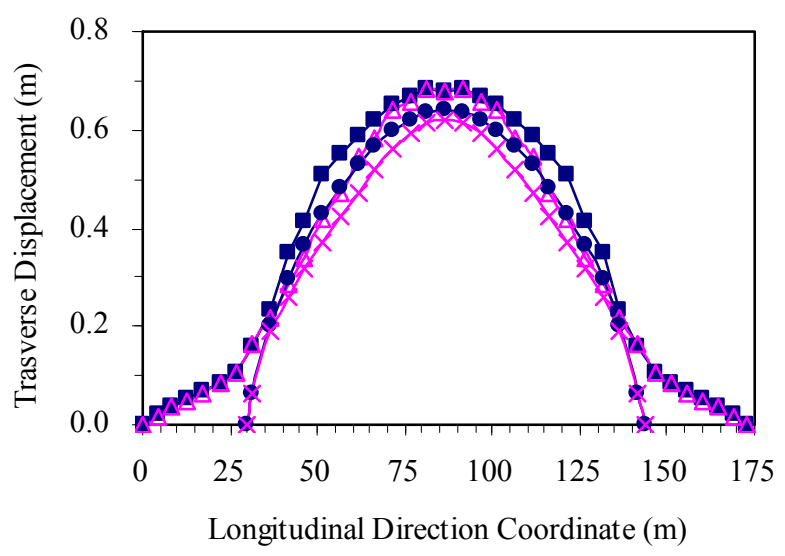

(e) Model 5

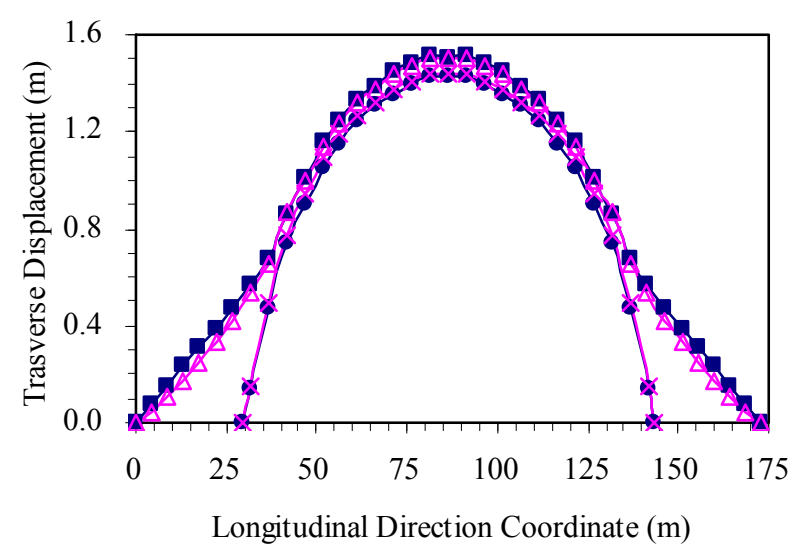

(b) Model 2

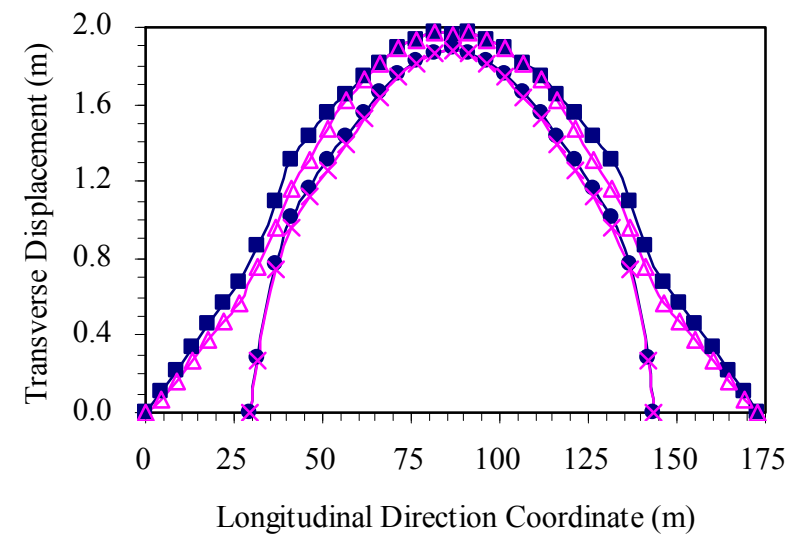

(d) Model 4

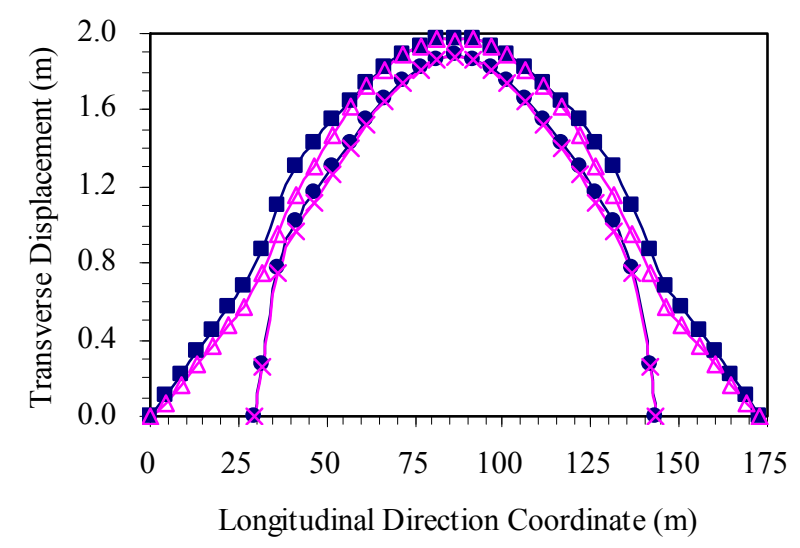

(f) Model 6

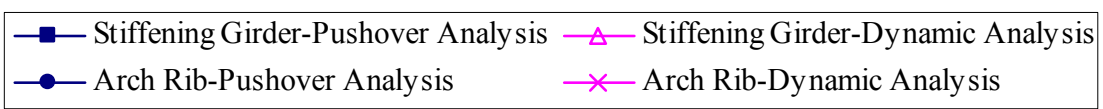

Figure 7: Displacement distributions for pushover and dynamic response analysis 


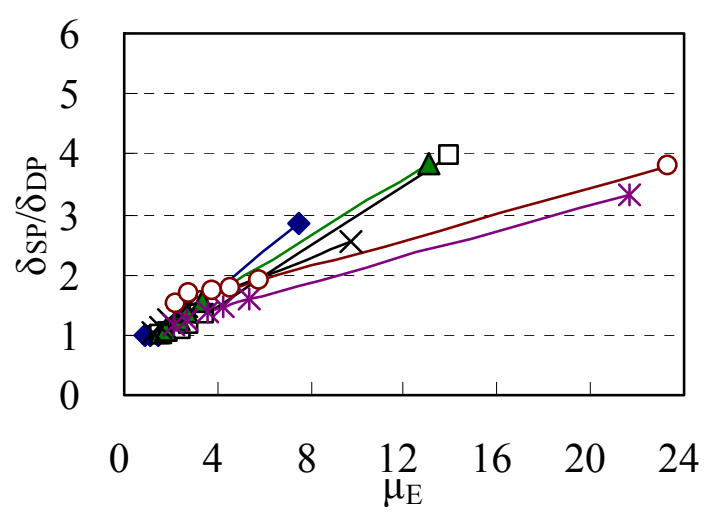

(a) Le2.t211, $\times 1.2, \times 1.5, \times 1.7, \times 2, \times 5$ (Ground Condition I)

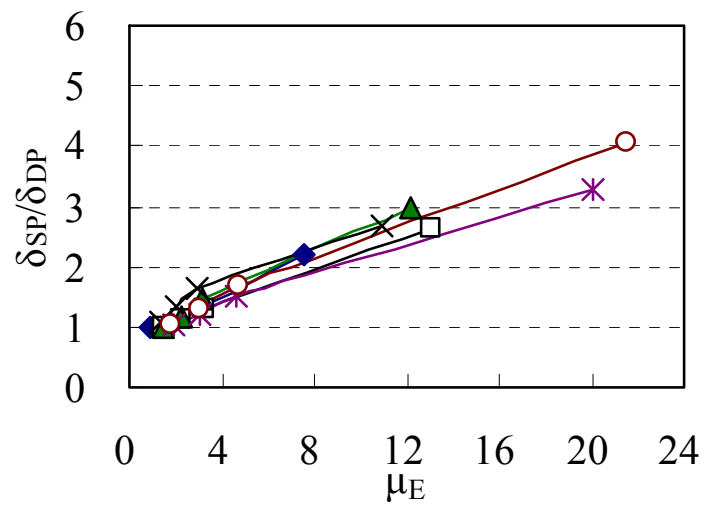

(c) Le2.t212, $\times 1.5, \times 2, \times 5$ (Ground Condition I)

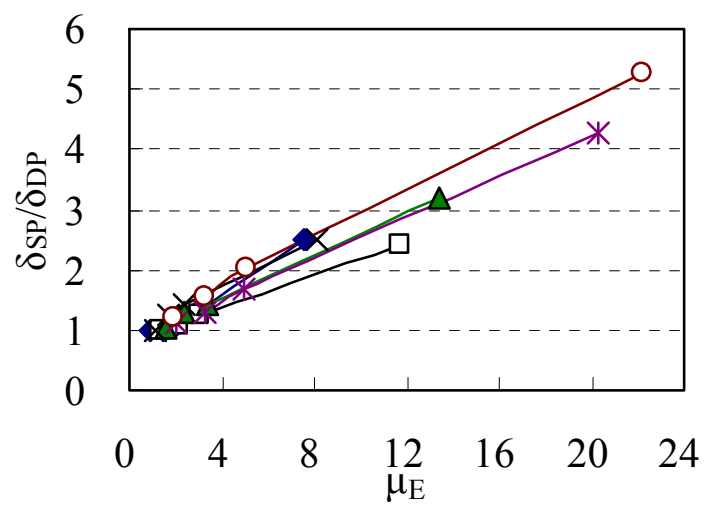

(e) Le2.t213, $\times 1.5, \times 2, \times 5$

(Ground Condition I)

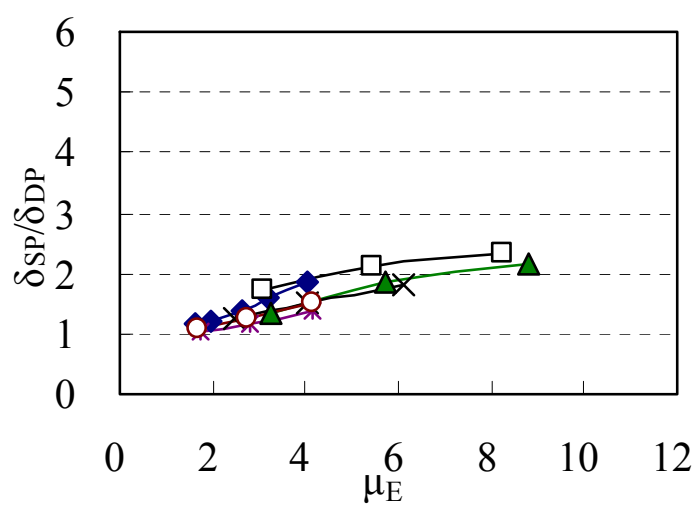

(b) Le2.t221, $\times 1.5, \times 2$

(Ground Condition II)

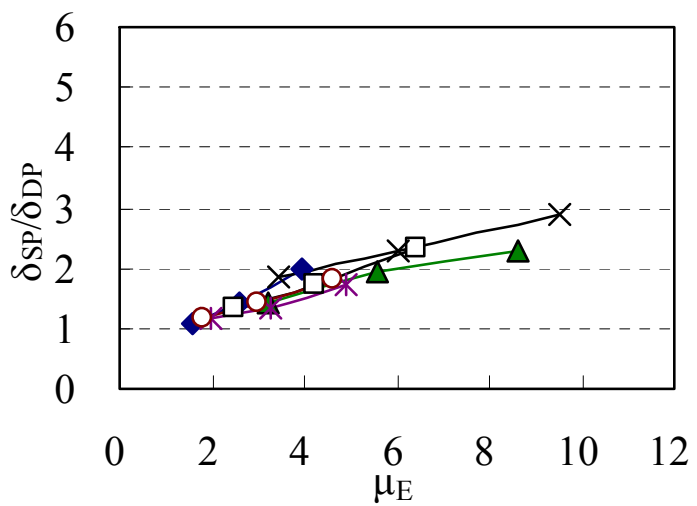

(d) Le2.t222, ×1.5, $\times 2$

(Ground Condition II)

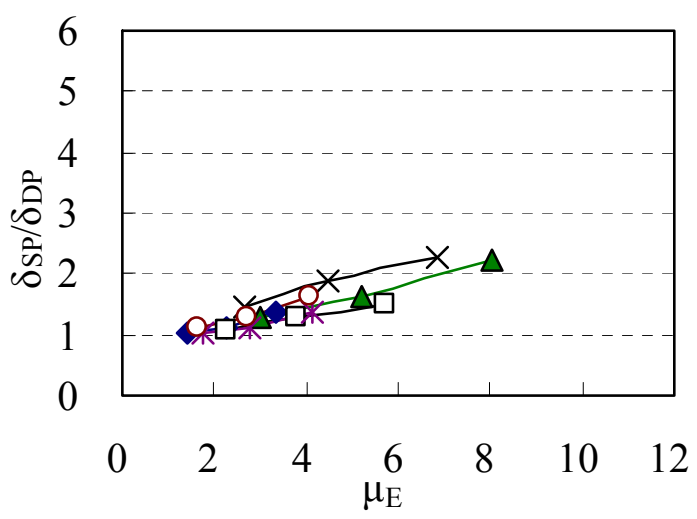

(f) Le2.t223, $\times 1.5, \times 2$

(Ground Condition II)

- Model $1 \quad \times$ Model 4

$\square$ Model $2 \quad *$ Model 5

$\triangle$ Model $3 \quad$ O Model 6

Figure 8: $\delta_{S P} / \delta_{D P}-\mu_{E}$ relationships for individual ground Motions 


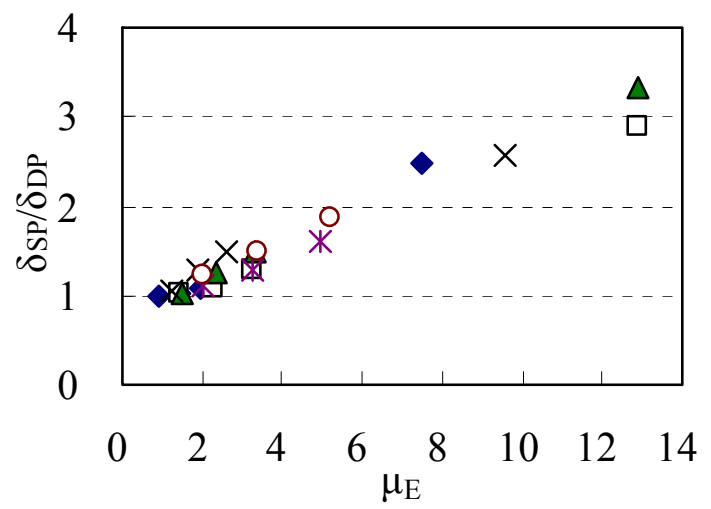

(a) Ground condition I

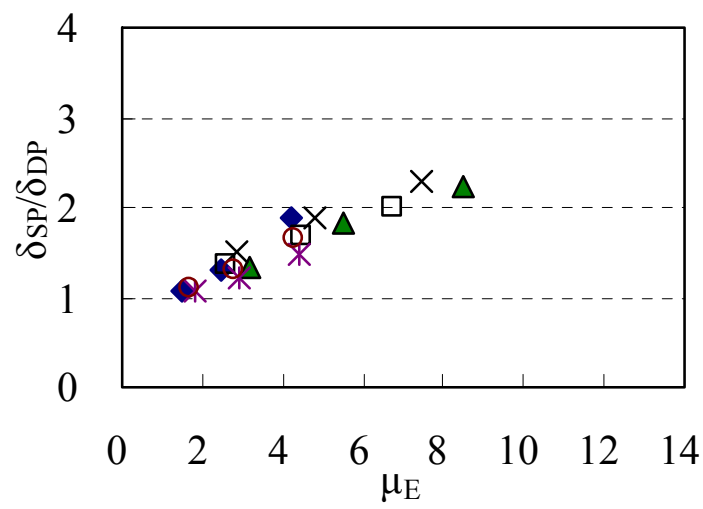

(b) Ground condition II

- Model $1 \quad \times$ Model 4

$\square$ Model $2 \quad *$ Model 5

$\Delta$ Model 3 O Model 6

Figure 9: $\delta_{S P} / \delta_{D P}-\mu_{E}$ relationships for average response displacements

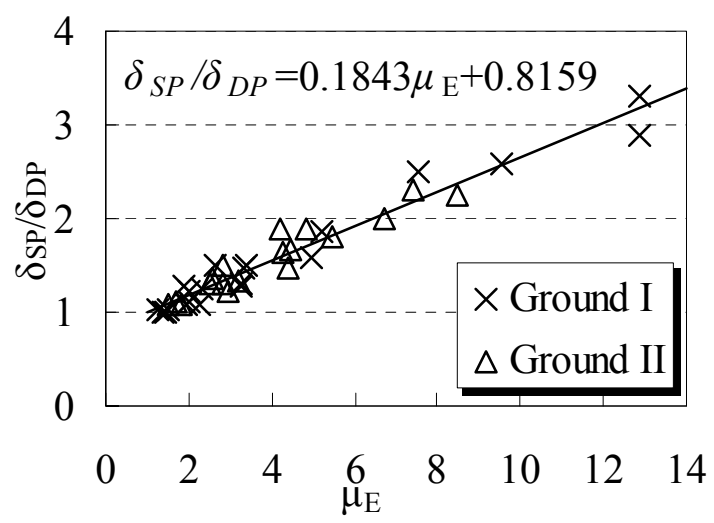

(a) Average approximation

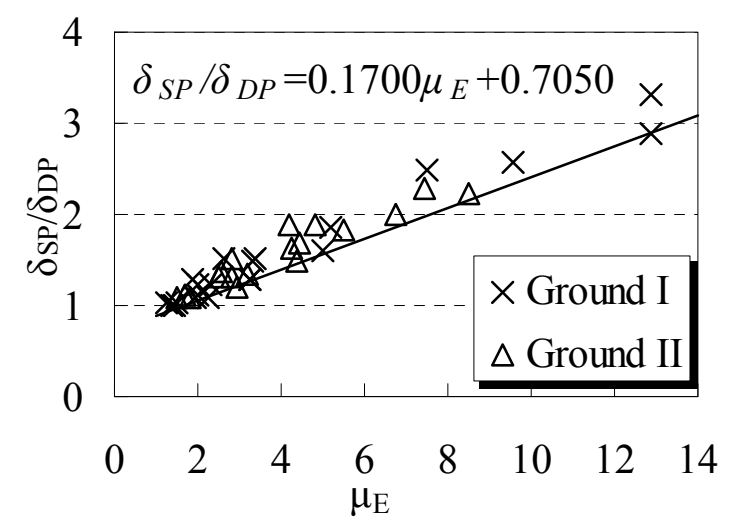

(b) Lower bound approximation

Figure 10: Approximation of $\delta_{S P} / \delta_{D P}-\mu_{E}$ relationship 


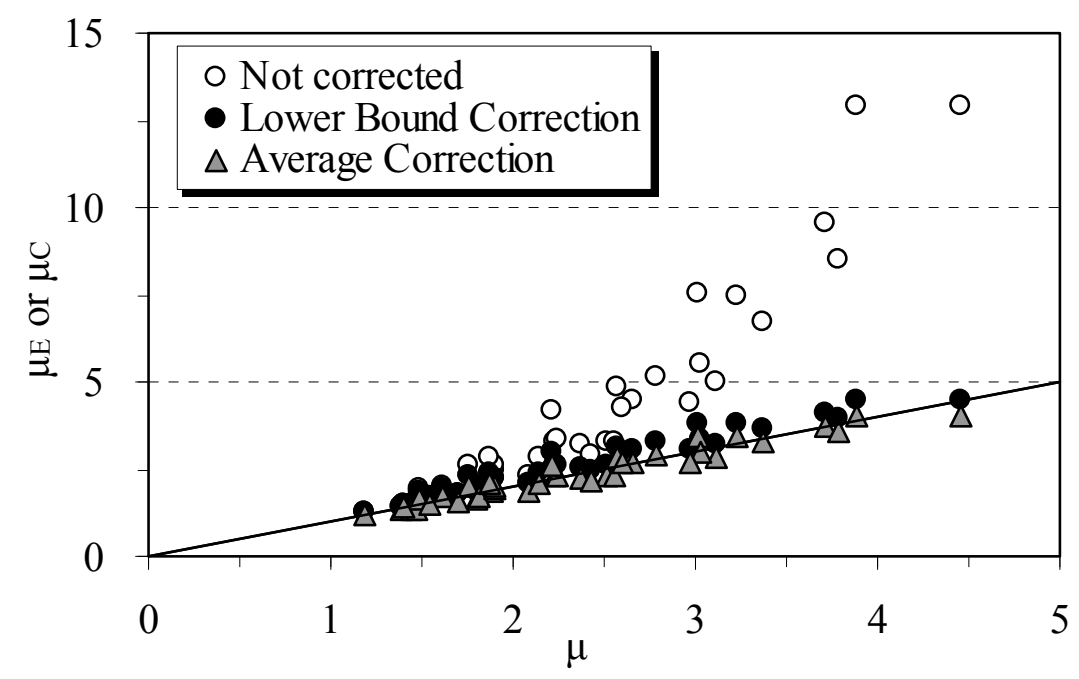

Figure 11: Correction results for the average response displacements

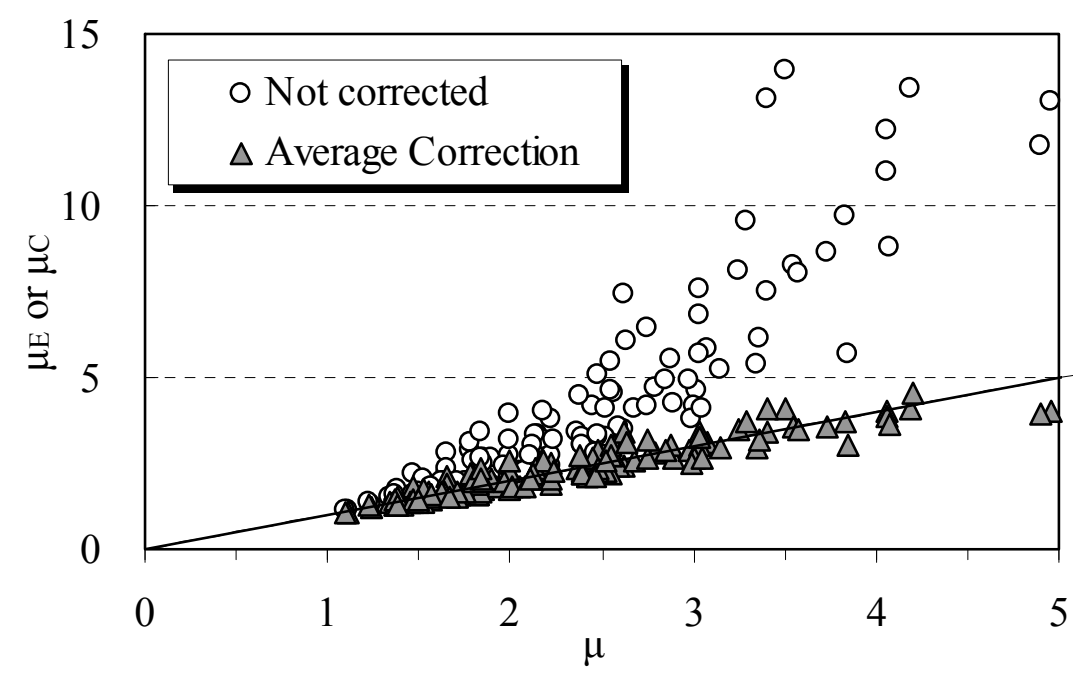

Figure 12: Correction results for the individual ground motions 


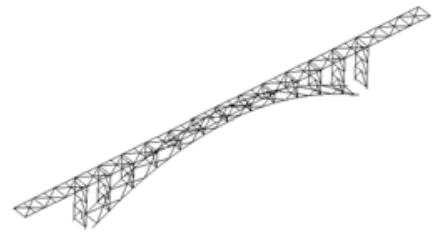

(a) Establish analytical FEM model

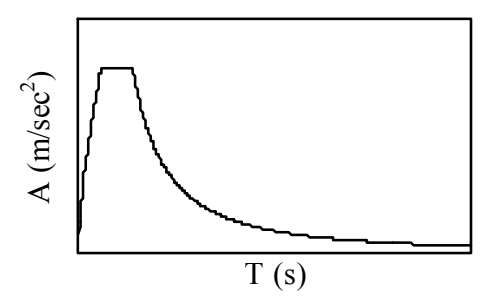

(d) Get the maximum elastic response from the response spectrum for level-II ground motion

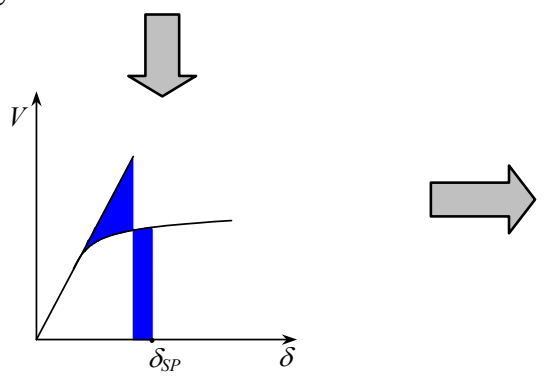

(e) Estimate the maximum inelastic response by equal energy assumption
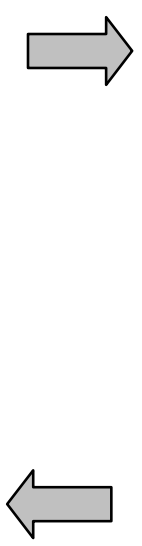

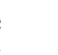




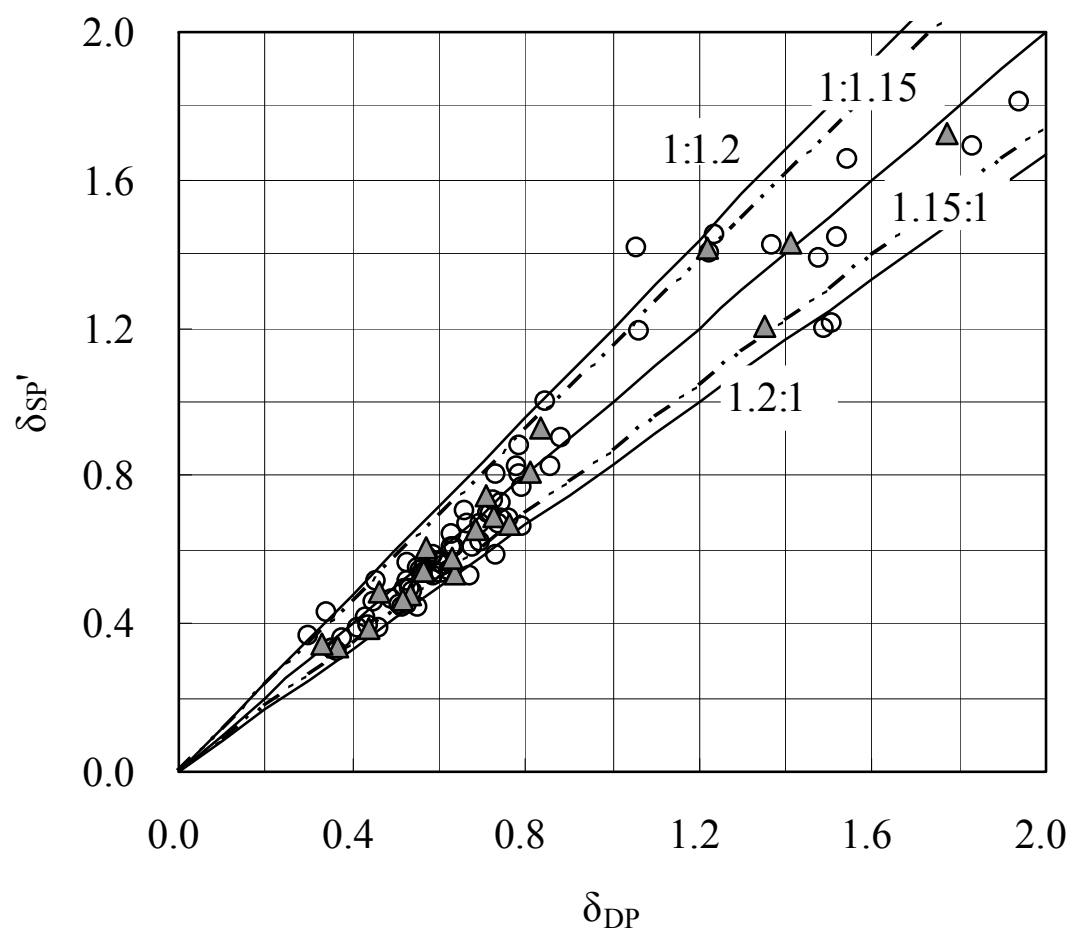

Ground Condition I

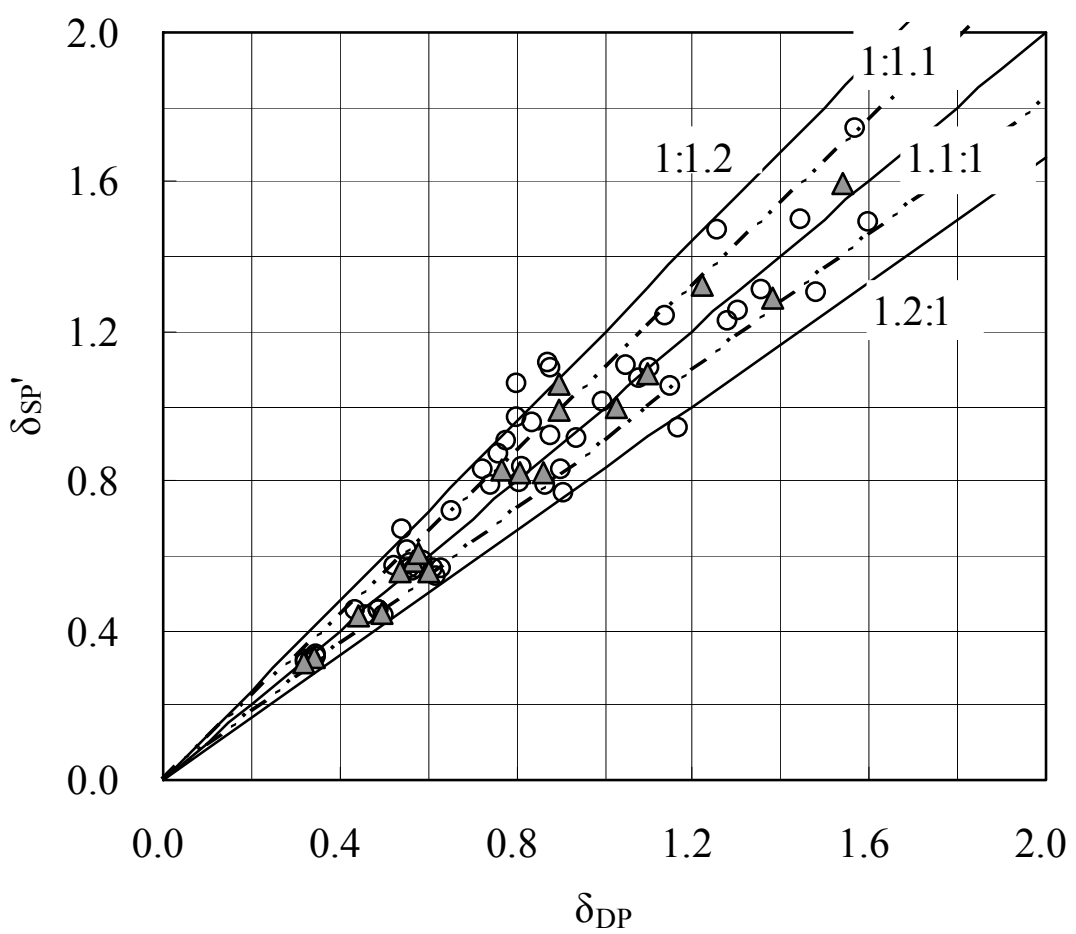

Ground Condition II

Average Estimation Results for the Individual Ground Motions

$\triangle$ Average Estimation Results for Average Response Displacements

Figure 14: Average estimation results with the proposed method. 


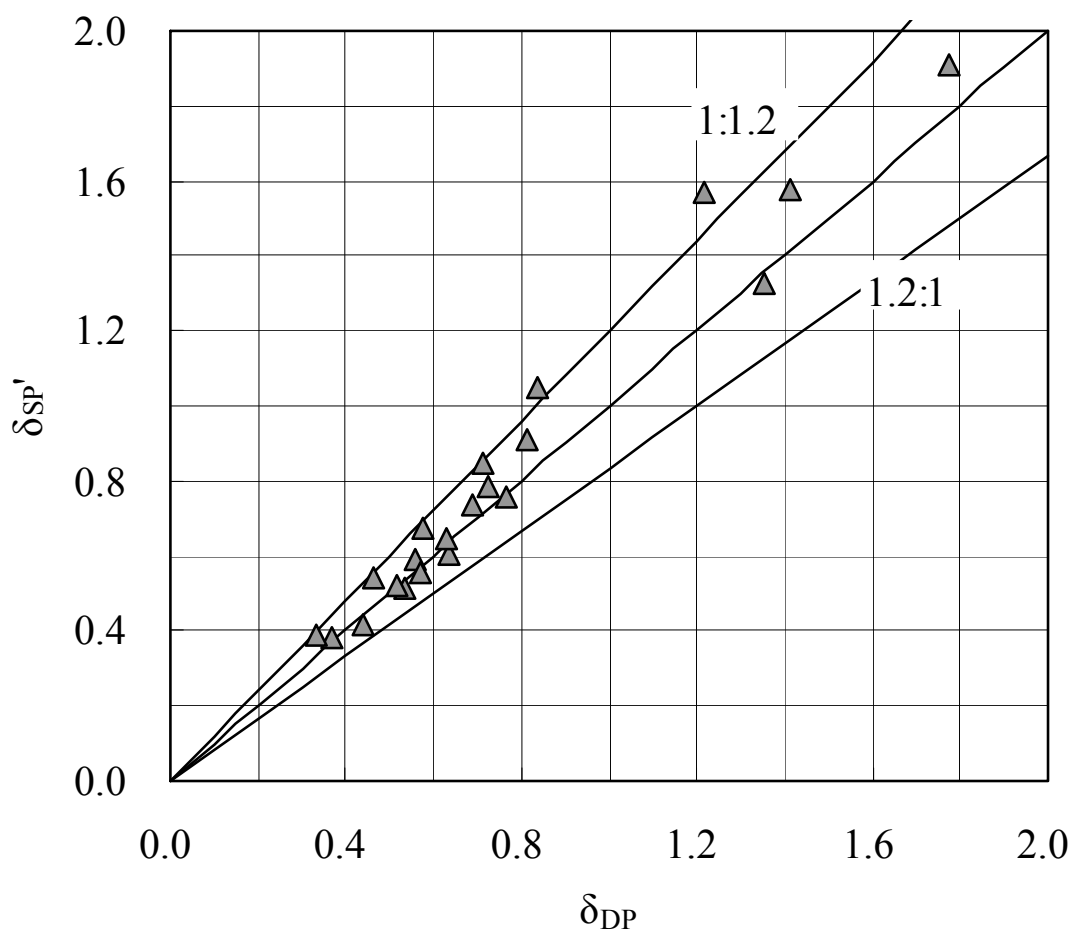

Ground Condition I

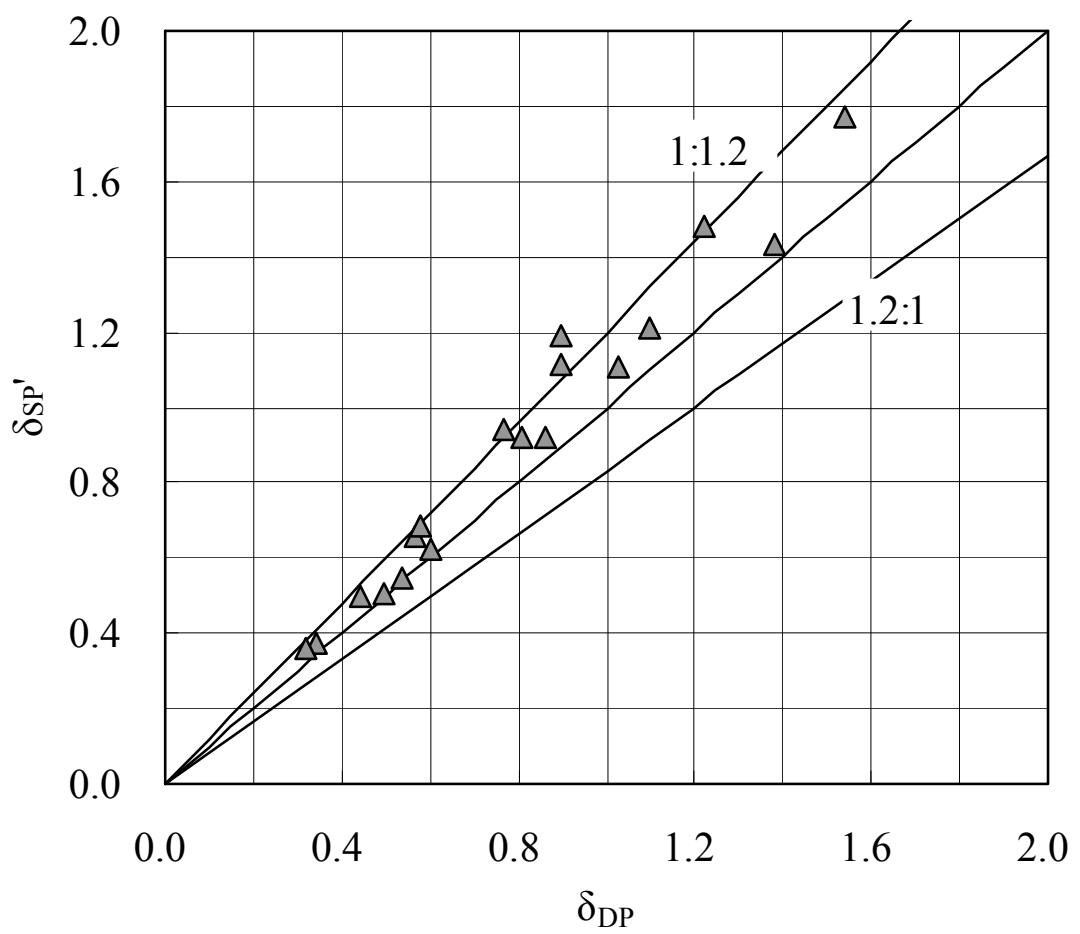

Ground Condition II

Figure 15: Lower bound estimation results with the proposed method 


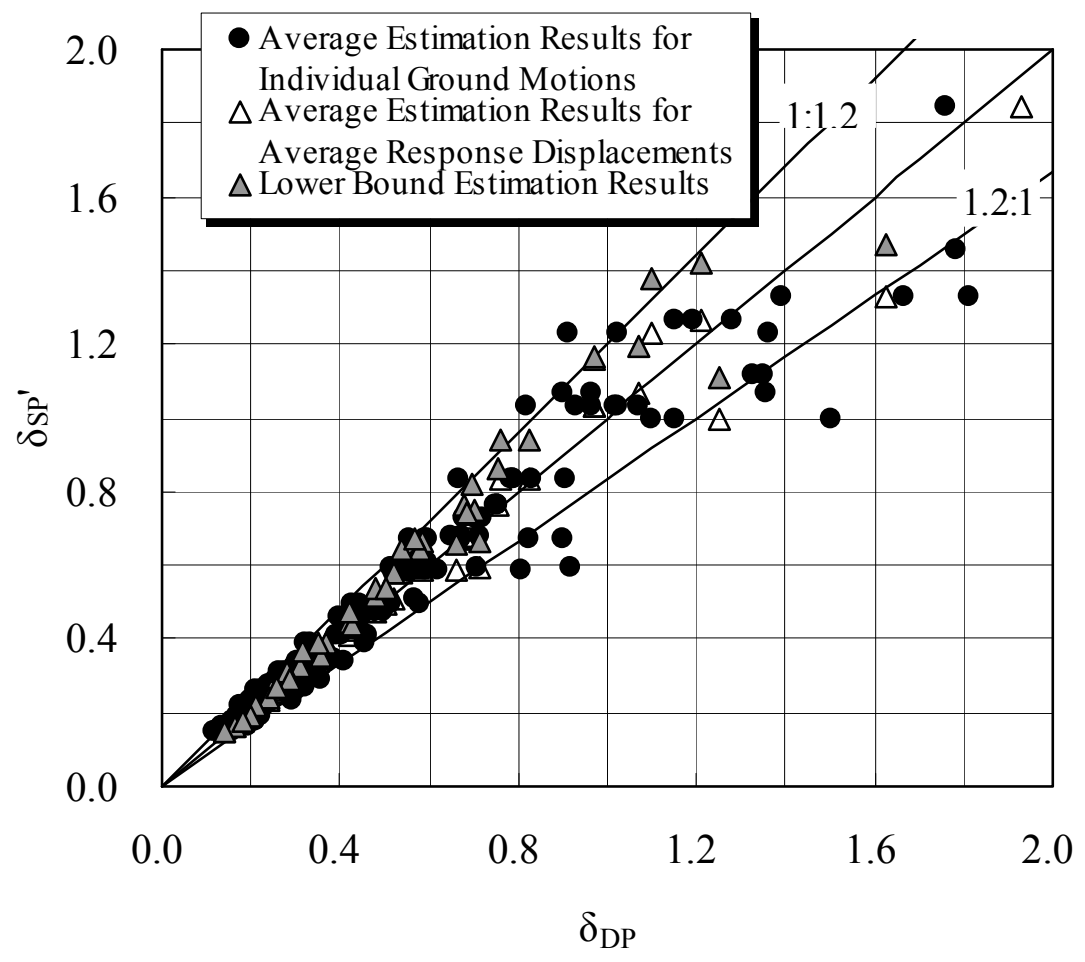

Figure 16: Estimation accuracy for the type I ground motions 
Table 1: Structural parameters of the analyzed models

\begin{tabular}{|c|c|c|c|c|}
\hline Model No. & Span Length (m) & Arch Rise (m) & $\frac{\text { Arch Rise }}{\text { Span Length }}$ & $\begin{array}{c}\text { Arch Rib } \\
\text { Spacing (m) }\end{array}$ \\
\hline Model 1 & 114 & 16.87 & 0.15 & 6.0 \\
Model 2 & 114 & 22.80 & 0.20 & 6.0 \\
Model 3 & 114 & 34.20 & 0.30 & 6.0 \\
Model 4 & 114 & 45.60 & 0.40 & 6.0 \\
Model 5 & 114 & 16.87 & 0.15 & 9.5 \\
Model 6 & 114 & 16.87 & 0.15 & 13 \\
\hline
\end{tabular}


Table 2: Eigenvalue analysis results

\begin{tabular}{|c|c|c|c|c|c|c|}
\hline \multirow[b]{2}{*}{ Model } & \multirow[b]{2}{*}{ Mode } & \multirow{2}{*}{$\begin{array}{c}\text { Natural } \\
\text { Frequency } \\
(\mathrm{Hz})\end{array}$} & \multicolumn{3}{|c|}{ Effective Mass Ratio } & \multirow[b]{2}{*}{ Deflection Mode } \\
\hline & & & Longitudinal (\%) & Transverse $(\%)$ & Vertical (\%) & \\
\hline \multirow{10}{*}{1} & 1 & 0.788 & 20.03 & 0.00 & 0.00 & In-plane \\
\hline & 2 & 1.041 & 0.00 & 60.67 & 0.00 & Out-of-plane \\
\hline & 3 & 1.696 & 0.00 & 0.00 & 0.00 & Out-of-plane \\
\hline & 4 & 1.846 & 0.00 & 0.00 & 0.84 & In-plane \\
\hline & 5 & 2.590 & 0.00 & 14.19 & 0.00 & Out-of-plane \\
\hline & 6 & 2.960 & 6.96 & 0.00 & 0.00 & In-plane \\
\hline & 7 & 3.197 & 0.00 & 0.00 & 46.60 & In-plane \\
\hline & 8 & 3.356 & 0.00 & 0.00 & 0.00 & Out-of-plane \\
\hline & 9 & 3.549 & 0.00 & 5.14 & 0.00 & In-plane \\
\hline & 10 & 3.709 & 0.00 & $0.00 \%$ & 21.90 & Local mechanism \\
\hline \multirow{10}{*}{2} & 1 & 0.744 & 35.09 & 0.00 & 0.00 & In-plane \\
\hline & 2 & 0.995 & 0.00 & 67.58 & 0.00 & Out-of-plane \\
\hline & 3 & 1.502 & 0.00 & 0.00 & 0.00 & Out-of-plane \\
\hline & 4 & 1.701 & 0.00 & 0.00 & 0.11 & In-plane \\
\hline & 5 & 2.204 & 0.00 & 13.36 & 0.00 & Out-of-plane \\
\hline & 6 & 2.745 & 24.85 & 0.00 & 0.00 & In-plane \\
\hline & 7 & 3.026 & 0.00 & 0.00 & 0.00 & Out-of-plane \\
\hline & 8 & 3.143 & 17.13 & 0.00 & 0.00 & Local mechanism \\
\hline & 9 & 3.369 & 0.00 & 0.00 & 2.28 & Local mechanism \\
\hline & 10 & 3.657 & 5.51 & 0.00 & 0.00 & Local mechanism \\
\hline \multirow{10}{*}{3} & 1 & 0.785 & 55.94 & 0.00 & 0.00 & In-plane \\
\hline & 2 & 0.824 & 0.00 & 68.93 & 0.00 & Out-of-plane \\
\hline & 3 & 1.328 & 0.00 & 0.00 & 0.00 & Out-of-plane \\
\hline & 4 & 1.884 & 0.00 & 0.00 & 0.17 & In-plane \\
\hline & 5 & 2.014 & 0.00 & 12.25 & 0.00 & Out-of-plane \\
\hline & 6 & 2.690 & 1.14 & 0.00 & 0.00 & In-plane \\
\hline & 7 & 2.866 & 0.00 & 0.00 & 0.00 & Out-of-plane \\
\hline & 8 & 3.262 & 0.00 & 0.00 & 2.06 & Local mechanism \\
\hline & 9 & 3.308 & 11.79 & 0.00 & 0.00 & Local mechanism \\
\hline & 10 & 3.679 & 0.00 & 1.69 & 0.00 & Out-of-plane \\
\hline \multirow{10}{*}{4} & 1 & 0.580 & 67.68 & 0.00 & 0.00 & In-plane \\
\hline & 2 & 0.647 & 0.00 & 71.99 & 0.00 & Out-of-plane \\
\hline & 3 & 1.127 & 0.00 & 0.00 & 0.00 & Out-of-plane \\
\hline & 4 & 1.563 & 0.00 & 0.00 & 0.72 & In-plane \\
\hline & 5 & 1.839 & 0.00 & 9.58 & 0.00 & Out-of-plane \\
\hline & 6 & 1.952 & 2.26 & 0.00 & 0.00 & Local mechanism \\
\hline & 7 & 2.053 & 0.00 & 0.00 & 0.40 & Local mechanism \\
\hline & 8 & 2.460 & 3.41 & 0.00 & 0.00 & In-plane \\
\hline & 9 & 2.671 & 0.00 & 0.00 & 0.00 & Out-of-plane \\
\hline & 10 & 2.842 & 0.00 & 0.14 & 0.00 & Local mechanism \\
\hline \multirow{10}{*}{5} & 1 & 0.811 & 22.16 & 0.00 & 0.00 & In-plane \\
\hline & 2 & 1.315 & 0.00 & 63.39 & 0.00 & Out-of-plane \\
\hline & 3 & 1.659 & 0.00 & 0.00 & 0.92 & In-plane \\
\hline & 4 & 1.905 & 0.00 & 0.00 & 0.00 & Out-of-plane \\
\hline & 5 & 2.447 & 49.95 & 0.00 & 0.00 & In-plane \\
\hline & 6 & 2.723 & 0.00 & 13.15 & 0.00 & Out-of-plane \\
\hline & 7 & 3.132 & 12.09 & 0.00 & 0.00 & In-plane \\
\hline & 8 & 3.267 & 0.00 & 0.00 & 48.42 & In-plane \\
\hline & 9 & 3.423 & 0.00 & 0.64 & 0.00 & Out-of-plane \\
\hline & 10 & 3.835 & 0.00 & 0.00 & 14.23 & In-plane \\
\hline
\end{tabular}


Table 2 (Continued)

\begin{tabular}{|c|c|c|c|c|c|c|}
\hline \multirow[b]{2}{*}{ Model } & \multirow[b]{2}{*}{ Mode } & \multirow{2}{*}{$\begin{array}{c}\text { Natural } \\
\text { Frequency } \\
(\mathrm{Hz})\end{array}$} & \multicolumn{3}{|c|}{ Effective Mass Ratio (\%) } & \multirow[b]{2}{*}{ Deflection Mode } \\
\hline & & & Longitudinal & Transverse & Vertical & \\
\hline \multirow{10}{*}{6} & 1 & 0.777 & 22.62 & 0.00 & 0.00 & In-plane \\
\hline & 2 & 1.363 & 0.00 & 61.59 & 0.00 & Out-of-plane \\
\hline & 3 & 1.582 & 0.00 & 0.00 & 1.16 & In-plane \\
\hline & 4 & 1.739 & 0.00 & 0.00 & 0.00 & Out-of-plane \\
\hline & 5 & 2.238 & 55.26 & 0.00 & 0.00 & In-plane \\
\hline & 6 & 2.323 & 0.00 & 12.22 & 0.00 & Out-of-plane \\
\hline & 7 & 2.964 & 8.29 & 0.00 & 0.00 & In-plane \\
\hline & 8 & 3.012 & 0.00 & 0.00 & 49.94 & In-plane \\
\hline & 9 & 3.121 & 0.00 & 0.01 & 0.00 & Out-of-plane \\
\hline & 10 & 3.777 & 0.00 & 0.00 & 10.03 & In-plane \\
\hline
\end{tabular}


Table 3: Input ground motions for the dynamic response analysis

\begin{tabular}{|c|c|c|c|c|}
\hline $\begin{array}{l}\text { Ground } \\
\text { Condition }\end{array}$ & Name & $\begin{array}{l}\text { Duration } \\
\quad(\mathrm{sec})\end{array}$ & $\begin{array}{l}\text { Maximum } \\
\text { Acceleration } \\
\left(\mathrm{cm} / \mathrm{sec}^{2}\right)\end{array}$ & Amplification \\
\hline \multirow{3}{*}{$\begin{array}{l}\text { Ground I } \\
\text { (Stiff) }\end{array}$} & $\begin{array}{c}1995 \text { JMA Kobe OBS N-S } \\
(\text { Le2.t211) }\end{array}$ & 30 & 812 & $\begin{array}{c}1.2,1.5,1.7 \\
2,5\end{array}$ \\
\hline & $\begin{array}{c}1995 \text { JMA Kobe OBS E-W } \\
\text { (Le2.t212) }\end{array}$ & 30 & 766 & $1.5,2,5$ \\
\hline & $\begin{array}{c}1995 \text { HEPC Inagawa N-S } \\
(\text { Le2.t213) }\end{array}$ & 30 & 780 & $1.5,2,5$ \\
\hline \multirow{3}{*}{$\begin{array}{l}\text { Ground II } \\
\text { (Moderate) }\end{array}$} & $\begin{array}{c}1995 \text { JR Takatori Sta. N-S } \\
\text { (Le2.t221) }\end{array}$ & 40 & 687 & $1.5,2$ \\
\hline & $\begin{array}{c}1995 \text { JR Takatori Sta. E-W } \\
\text { (Le2.t222) }\end{array}$ & 40 & 673 & $1.5,2$ \\
\hline & $\begin{array}{c}1995 \text { OGAS Fukiai N27W } \\
(\text { Le2.t223) }\end{array}$ & 40 & 736 & $1.5,2$ \\
\hline
\end{tabular}

